\title{
Life-Sustaining Treatment Decisions Initiative: Early Implementation Results of a National Veterans Affairs Program to Honor Veterans' Care Preferences
}

\author{
Cari Levy, MD, $P h D^{1,2}$ (D), Mary Ersek, PhD, RN, FPCN ${ }^{3,4,5}$, Winifred Scott, MPH', \\ Joan G. Carpenter, PhD, CRNP, FPCN ${ }^{3,4}$, Jennifer Kononowech, LMSW', \\ Ciaran Phibbs, $P h D^{6}$, Jill Lowry, PsyD ${ }^{8}$, Jennifer Cohen, $P h D, M P H^{8,9}$, and \\ Marybeth Foglia, $R N, P h D, M A^{8,10}$
}

'Department of Veterans Affairs, Rocky Mountain VA Medical Center, Aurora, CO, USA; ${ }^{2}$ Division of Health Care Policy and Research, University of Colorado School of Medicine, Aurora, CO, USA; ${ }^{3}$ Department of Veterans Affairs, Corporal Michael J. Crescenz VA Medical Center, Philadelphia, PA, USA; ${ }^{4}$ University of Pennsylvania School of Nursing, Philadelphia, PA, USA; ${ }^{5}$ Perelman School of Medicine at the University of Pennsylvania, Philadelphia, PA, USA; ${ }^{6}$ Department of Veterans Affairs, Palo Alto, CA, USA; ${ }^{7}$ Department of Veterans Affairs, Ann Arbor Center for Clinical Management Research, Ann Arbor, MI, USA; ${ }^{8}$ Department of Veterans Affairs, National Center for Ethics in Health Care, Washington, DC, USA; ${ }^{9}$ Department of Epidemiology, University of Washington School of Public Health, Seattle, WA, USA; ${ }^{10}$ Department of Bioethics and Humanities, University of Washington School of Medicine, Seattle, WA, USA.

BACKGROUND: On July 1, 2018, the Veterans Health Administration (VA) National Center for Ethics in Health Care implemented the Life-Sustaining Treatment Decisions Initiative (LSTDI). Its goal is to identify, document, and honor LST decisions of seriously ill veterans. Providers document veterans' goals and decisions using a standardized LST template and order set.

OBJECTIVE: Evaluate the first 7 months of LSTDI implementation and identify predictors of LST template completion.

DESIGN: Retrospective observational study of clinical and administrative data. We identified all completed LST templates, defined as completion of four required template fields. Templates also include four non-required fields. Results were stratified by risk of hospitalization or death as estimated by the Care Assessment Need (CAN) score.

SUBJECTS: All veterans with VA utilization between July 1, 2018, and January 31, 2019.

MAIN MEASURES: Completed LST templates, goals and LST preferences, and predictors of documentation.

RESULTS: LST templates were documented for 108,145 veterans, and $85 \%$ had one or more of the non-required fields completed in addition to the required fields. Approximately half documented a preference for cardiopulmonary resuscitation. Among those who documented specific goals, half wanted to improve or maintain function, independence, and quality of life while $28 \%$ had a goal of life prolongation irrespective of risk of hospitalization/ death and $45 \%$ expressed a goal of comfort. Only $7 \%$ expressed a goal of being cured. Predictors of documentation included VA nursing home residence, older age, frailty, and comorbidity, while non-Caucasian race, rural residence, and receipt of care in a lower complexity medical center were predictive of no documentation.

Received August 30, 2019

Accepted January 31, 2020

Published online February 24, 2020
CONCLUSIONS: LST decisions were documented for veterans at high risk of hospitalization or death. While few expressed a preference for cure, half desire, cardiopulmonary resuscitation. Predictors of documentation were generally consistent with existing literature. Opportunities to reduce observed disparities exist by leveraging available VA resources and programs.

KEY WORDS: end of life; seriously ill; veteran.

J Gen Intern Med 35(6): 1803-12 DOI: $10.1007 /$ s11606-020-05697-2

(C) Society of General Internal Medicine (This is a U.S. government work and not under copyright protection in the U.S.; foreign copyright protection may apply) 2020

\section{BACKGROUND}

Care of persons with serious, life-limiting illnesses requires open, ongoing communication and documentation of the person's values, goals, and preferences for life-sustaining treatments (LSTs). ${ }^{1,2}$ The Physician Orders for Life-Sustaining Treatments (POLST) paradigm is widely used to translate goals and preferences for LSTs among those with lifelimiting illness into actionable medical orders. These orders accompany patients across care settings and direct the response of emergency personnel. Studies indicate that POLST completion is associated with preference-sensitive care. ${ }^{3-6}$

Despite the promise and successes of the POLST paradigm, ${ }^{7}$ participation in the program is low, including among veterans, ${ }^{8}$ and implementation challenges remain. For example, accessibility of the POLST is variable and portability often relies on physically transporting hard copy across care settings, a process that is prone to errors. Moreover, the orders must be integrated into the health record and available at the point of care. Only a few states, most notably Oregon, ${ }^{9}$ and several healthcare systems ${ }^{10}$ maintain a state- or system-wide registry of POLST 
forms that are widely accessible across settings. POLST forms are completed for patients who have a very short life expectancy as well as those who will spend many years living with serious illness. ${ }^{11,12}$ Moreover, many clinicians lack the skills and confidence to conduct robust goals of care conversations, which may result in inaccurate or incomplete representations of patient preferences. ${ }^{13-17}$ Like advance directives, POLST forms can also be misinterpreted. ${ }^{18,19}$ Finally, a systematic implementation of POLST programs and ongoing quality improvement efforts are sporadic. $^{13,20}$

Adapting and improving upon the POLST paradigm, the Veterans Health Administration (VA) National Center for Ethics in Healthcare (NCEHC) began implementing an initiative across VA's national healthcare system. Based on available evidence cited above, the VA updated its policy and established practice standards for eliciting, documenting, and honoring seriously ill veterans' goals of care and LST decisions. ${ }^{21}$ The policy is one component of the Life-Sustaining Treatment Decisions Initiative (LSTDI), a multi-pronged, evidence-based, cultural change initiative. This multicomponent program includes the following: (1) high-level leadership engagement and buy-in; (2) comprehensive, interdisciplinary staff education and communication skills training in conducting and documenting goals of care conversations (GoCCs); (3) a standardized, durable, and portable LST template and order set that are embedded in the EHR; (4) technology tools to identify high-risk patients, monitor implementation, and promote quality improvement; and (5) a program to evaluate short- and long-term outcomes of the LSTDI. ${ }^{22}$ The policy requires practitioners to initiate proactive GoCCs with veterans (or their designated surrogate decision-maker) who are at a high risk of a life-threatening clinical event in the next 1-2 years. Practitioners document these conversations and decisions in an LST template and order set in the electronic healthcare record (EHR). This policy change allows for extraction and monitoring of LST preference documentation. Prior to this policy change, LST preferences could not be extracted from the VA EHR.

The purpose of this exploratory analysis was to (1) evaluate early implementation of the LSTDI across the VA's healthcare system as demonstrated in the number and completeness of LST templates and order sets; (2) characterize the goals and LST decisions of veterans with completed LST templates; and (3) identify predictors of documenting preferences on the standardized LST template. As such, this paper is the first to document the comprehensive implementation of a program using an adaptation of the POLST paradigm in a national healthcare system.

\section{METHODS}

Data for this analysis were extracted from the VA's Corporate Data Warehouse (CDW), which integrates databases containing electronic medical records, the Managerial Cost
Accounting System, Medical SAS datasets, the Vital Status File, the Assistant Deputy Under Secretary for Health Enrollment Files, and other administrative data sources (http://www.hsrd. research.va.gov/for_researchers/vinci/cdw.cfm). The cohort included 5,576,279 veterans who used VA-provided or VApurchased care between July 1, 2018, and January 31, 2019 (defined as having recorded cost data during this period). Veterans were assigned to one of 137 facilities based on where the veterans received most of their care during the 7-month study time frame. We excluded veterans who received care at any of the four LSTDI demonstration sites which had established proof of concept prior to national rollout. ${ }^{22}$ Veterans assigned to Manila, Philippines. also were excluded because of fundamental differences in the structure of the care systems (see Fig. 1).

LST Template. The standardized template and order set entitled "Life-Sustaining Treatment" (Fig. 2) consists of eight fields, four of which are mandatory: The mandatory elements are decision-making capacity; patient's goals of care (broad goals such as "to be cured" or "to be comfortable"); oral informed consent for the LST plan; and cardiopulmonary resuscitation [CPR] status. Veterans can elect more than one goal on the LST template. Templates with documented answers for the four mandatory fields are deemed completed. Once the template and associated LST orders are entered into the EHR, select data elements called LST health factors (i.e., computerized data elements that capture patient information for which no standard code exists) are stored in the CDW, where they can be retrieved and analyzed.

For the analysis, we included LST templates completed by January 31, 2019. For veterans with more than one LST template completed, only the most recent template was retained for analysis (Fig. 1).

Care Assessment Need Scores. Care Assessment Need (CAN) scores predict risk of three outcomes - hospitalization, mortality, and hospitalization/mortality - for two periods, 90 days and 1 year. Scores are available at the point of care for all veterans who are assigned a primary care provider. The score is based on patient characteristics including demographics, diagnoses, vital signs, utilization, pharmacy data, and laboratory values. Scores range from 0 (lowest risk) to 99 (highest risk) and are reported in increments of 5 from 0 to 94 and by 1 from 95 to 99. ${ }^{23,24}$ Veterans in the cohort were stratified into four categories based on their CAN score for the risk of hospitalization and/or mortality within 1 year. Those with a missing CAN score (e.g., veterans lacking an assigned primary care provider) were assigned to a fifth category. Because CAN scores change over time, we used the score closest to the study time frame (July 1, 2018-January 31, 2019) which involved searching for CAN scores within 90 days before the start of the study time frame (July 1,2018) and with 90 days after the end of the study time frame (January 31, 2019). We retained the CAN score that was closest to July 1, 2018. 


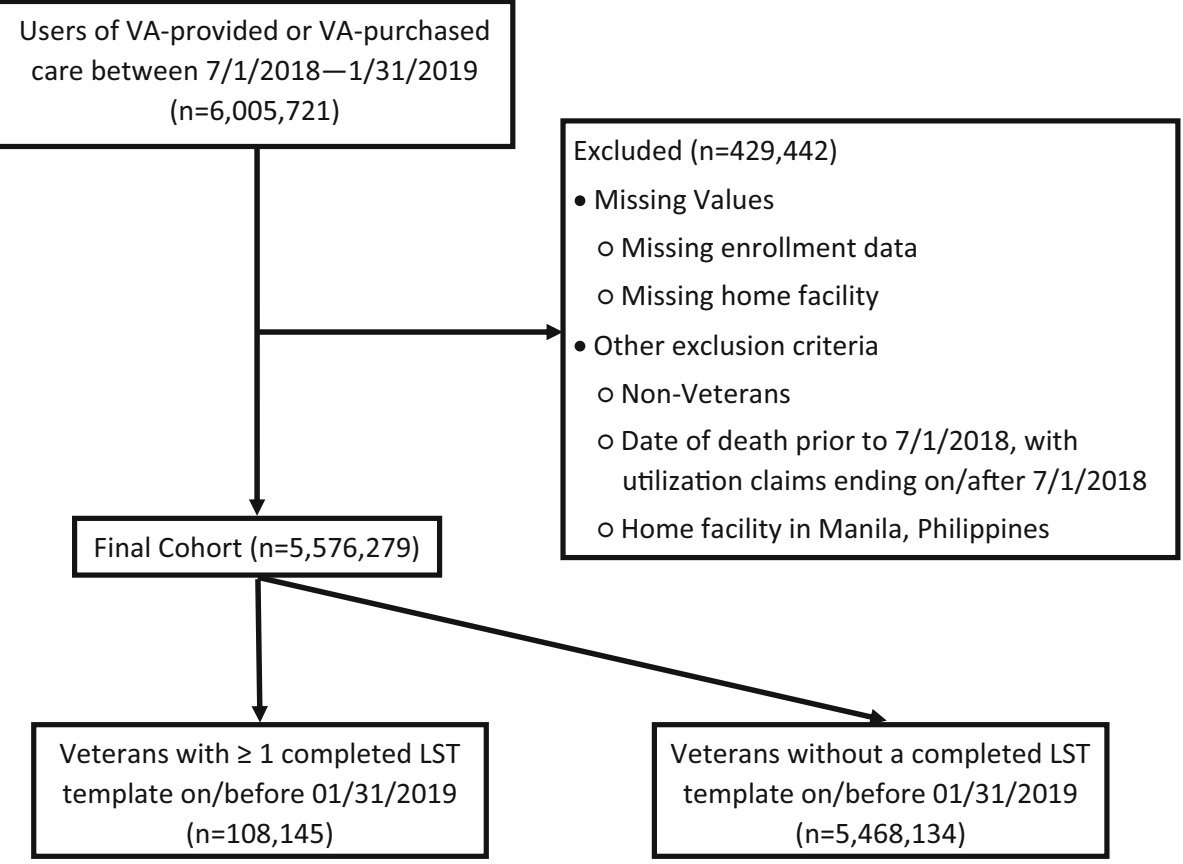

Figure 1 Cohort identification flowchart.

Covariates. Age, marital status, race/ethnicity gender, rurality of VA setting where veterans received majority of care, medical facility complexity (1a, 1b, 1c, 2, 3; lower number and letter indicates higher complexity), and stay in a VA nursing home were included as covariates in the analysis. We also included the $\mathrm{JEN}^{\mathrm{TM}}$ (JEN Associates) Frailty Index, which quantifies the risk of nursing home admission and is significantly associated with Medicare/Medicaid expenditures. A score of $0-2$ is considered low risk, 3-5 moderate risk, and $\geq 6$ high risk. ${ }^{25}$ Finally, as a measure of comorbidities associated with healthcare costs, we included the Center for Medicare \& Medicaid Services Hierarchical Condition Category (HCC) risk adjustment model. ${ }^{26}$

Analysis. The LSTDI encourages prioritization of veterans with CAN scores of 95-99; thus, we examined completion rates across four CAN score groupings $(<90,90-94,95-97$, 98-99). Within each CAN score category, chi-square tests were used to examine differences between veterans with and without a completed LST template. Wilcoxon's rank-sum tests were used to identify significant differences in the continuous variables. Logistic regression was used to describe patientand facility-level predictors of template completion after adjusting for CAN scores, VA nursing home stay, HCC score, $\mathrm{JEN}^{\mathrm{TM}}$ Frailty Index score, age, marital status, race/ethnicity, gender, rurality, and facility complexity. Continuous variables were categorized to create dummy indicators in the model. We used SAS Enterprise Guide 7.1 for table construction and STATA-MP V. 13.0 for all multivariate analyses.

Finally, we also examined the numbers of new and cumulative completed LST templates by month to assess for trends in completion following implementation of the initiative. As an indicator of the robustness of the GoCC and initiative effectiveness, we also calculated the percentage of LST templates with non-required fields completed.

The VA Office of Research and Development determined that this analysis was for quality improvement and not subject to human research regulations; thus, no IRB approval was obtained.

\section{RESULTS}

Among 5,576,279 veterans in the cohort, 108,145 veterans had a completed LST template (Table 1). Higher CAN scores were associated with higher LST completion rates; $24 \%$ of veterans with the highest scores (98-99) compared with $<1 \%$ of veterans with scores of $<90$ had completed templates. Completion was higher for older veterans across all CAN score categories; this difference was most pronounced in veterans with CAN scores of $98-99$, where $17 \%$ of those under age 65 had completed a template compared with $39 \%$ of veterans over age 90 . The mean age for veterans with a completed template was 70.2 for those with CAN scores of $<90$ and 74.3 in the highest CAN score group (Table 1).

The strongest predictor of template completion (Table 2) was the VA nursing home stay (OR 14.5, 95\% CI 14.1214.97). Other highly predictive patient-level factors included higher CAN scores, a JEN ${ }^{\mathrm{TM}}$ Frailty Index score of 6-13 (OR 12.5, 95\% CI 11.99-13.10), and an HCC score in the top quartile (OR 8.61, 95\% CI 8.14-9.11). Age older than 64 years and non-married status also predicted completion while Hispanic ethnicity (OR $0.87,95 \%$ CI $0.85-0.90$ ), all nonCaucasian race categories (African American OR 0.70, 95\% CI 0.69-0.72; American Indian/Alaskan Native OR 0.89, 95\% 


\begin{tabular}{|c|c|}
\hline \multicolumn{2}{|r|}{ Life-Sustaining Treatment (LST) Template and Orders } \\
\hline $\begin{array}{l}\text { *1. Does the patient have } \\
\text { capacity to make decisions } \\
\text { about life-sustaining } \\
\text { treatments? }\end{array}$ & $\begin{array}{l}\square \quad \text { The patient has capacity to make decisions about life-sustaining } \\
\text { treatments } \\
\square \quad \text { The patient lacks capacity to make decisions about life- } \\
\text { sustaining treatments and has a surrogate. } \\
\square \quad \text { The patient lacks capacity to make decisions about life- } \\
\text { sustaining treatments and has no surrogate. }\end{array}$ \\
\hline $\begin{array}{l}\text { 2. Who is the person authorized } \\
\text { under VA policy to make } \\
\text { decisions for the patient if/when } \\
\text { the patient loses decision- } \\
\text { making capacity? }\end{array}$ & $\begin{array}{l}\text { Authorized surrogate if/when the patient loses decision-making } \\
\text { capacity: ][text box] } \\
\text { The patient has no surrogate authorized to make health care } \\
\text { decisions if/when the patient loses decision-making capacity. }\end{array}$ \\
\hline $\begin{array}{l}\text { 3. Have you reviewed available } \\
\text { documents that reflect the } \\
\text { patient's wishes regarding life- } \\
\text { sustaining treatments? } \\
\text { Examples: advance directives, } \\
\text { state-authorized portable orders } \\
\text { (e.g., POLST, MOST), life- } \\
\text { sustaining treatment } \\
\text { templates/orders. }\end{array}$ & $\begin{array}{l}\square \text { No advance directive, state-authorized portable orders, or life - } \\
\text { sustaining treatment templates/orders were available in the } \\
\text { record or presented by the patient (or surrogate) [optional text } \\
\text { box] } \\
\square \quad \text { I reviewed with the patient (or surrogate) all active advance } \\
\text { directives (s), state-authorized portable orders, or life-sustaining } \\
\text { treatment templates/orders available in the record and/or } \\
\text { presented by the patient (or surrogate) }\end{array}$ \\
\hline $\begin{array}{l}\text { 4. Does the patient (or surrogate) } \\
\text { have sufficient understanding of } \\
\text { the patient's medical condition } \\
\text { to make informed decisions } \\
\text { about life-sustaining treatments? }\end{array}$ & $\begin{array}{l}\text { Yes. The patient's (or surrogate's) understanding is consistent } \\
\text { with the medical facts. } \\
\text { Other (e.g., the patient lacks decision-making capacity and has } \\
\text { no surrogate)[text box] }\end{array}$ \\
\hline $\begin{array}{l}\text { *5. What are the patient's } \\
\text { goals of care? (Select all that } \\
\text { apply. Do not attempt to rank } \\
\text { the goals of care here) }\end{array}$ & $\begin{array}{l}\square \quad \text { Patient's goals of care in their own words, or as stated by the } \\
\text { surrogate: } \\
\text { To be cured of: } \\
\text { To prolong life } \\
\square \quad \text { To improve or maintain function, independence, quality of life } \\
\square \quad \text { To be comfortable } \\
\square \quad \text { To obtain support for family/caregiver } \\
\square \quad \text { To achieve life goals, including: }\end{array}$ \\
\hline $\begin{array}{l}\text { 6. What is the current plan for } \\
\text { use of life-sustaining treatments? }\end{array}$ & $\begin{array}{l}\square \text { FULL SCOPE OF TREATMENT in circumstances OTHER } \\
\text { than cardiopulmonary arrest. } \\
\text { LIMIT LIFE-SUSTAINING TREATMENT, as follows: } \\
\text { Artificial Nutrition } \\
\circ \quad \text { No artificial nutrition (enteral or parenteral) } \\
\circ \quad \text { Limit artificial nutrition as follows: [text box] } \\
\text { Artificial Hydration } \\
\circ \quad \text { No artificial hydration (enteral, IV, or subcutaneous) } \\
\text { except if needed for comfort } \\
\circ \quad \text { Limit artificial hydration as follows: [text box] } \\
\text { Mechanical Ventilation } \\
\circ \quad \text { No invasive mechanical ventilation (e.g., endotracheal } \\
\quad \text { or tracheostomy tube) } \\
\quad \text { No non-invasive mechanical ventilation (e.g., CPAP, } \\
\quad \text { BiPAP) } \\
\circ \quad \text { Limit mechanical ventilation as follows: [text box] } \\
\text { Transfers between Levels of Care } \\
\circ \quad \text { No transfers to the ICU except if needed for comfort } \\
\circ \quad \text { No transfers to the hospital except if needed for } \\
\quad \text { comfort } \\
\circ \quad \text { Limit transfers as follows (e.g. patient wishes to remain } \\
\text { at home if possible): [text box] } \\
\text { Limit Other Life-Sustaining Treatment as follows (e.g., blood } \\
\text { products, dialysis): [text box] } \\
\text { NO LIFE-SUSTAINING TREATMENT in circumstances } \\
\text { OTHER than cardiopulmonary arrest. } \\
\text { *CARDIOPULMONARY RESUSCITATION (CPR) } \\
\text { Full Code: Attempt CPR } \\
\text { DNAR/DNR: Do not attempt CPR } \\
\text { DNAR/DNR with exception: ONLY attempt CPR during } \\
\text { the following procedure: [text box] }\end{array}$ \\
\hline $\begin{array}{l}\text { 7. Who participated in this } \\
\text { discussion? }\end{array}$ & $\begin{array}{l}\square \text { Document participants and other relevant information: [text } \\
\text { box] }\end{array}$ \\
\hline $\begin{array}{l}\text { *8. Who has given oral } \\
\text { informed consent for the life- } \\
\text { sustaining treatment plan } \\
\text { outlined above? }\end{array}$ & $\begin{array}{l}\square \text { The patient has given oral informed consent for the life- } \\
\text { sustaining treatment plan. } \\
\square \text { The surrogate has given oral informed consent for the life- } \\
\text { sustaining treatment plan. Name of the surrogate providing } \\
\text { consent: } \\
\square \text { The patient lacks decision-making capacity and has no surrogate. } \\
\text { o The LST plan has been approved through the } \\
\text { multidisciplinary committee review process. }\end{array}$ \\
\hline
\end{tabular}

Figure 2 Life-Sustaining Treatment (LST) template and orders. 
Table 1 Characteristics of Veterans Stratified by Care Assessment Need Score and with a Documented Life-Sustaining Treatment Template, $N=\mathbf{5 , 5 7 6 , 2 7 9}(n=\mathbf{1 0 8 , 1 4 5}$ with completed template; $n=5,468,134$ without completed template)

\begin{tabular}{|c|c|c|c|c|c|c|c|c|c|c|}
\hline & \multicolumn{10}{|c|}{ Care Assessment Need (CAN) score and associated risk of hospitalization or death } \\
\hline & \multicolumn{2}{|c|}{$\begin{array}{l}\text { Lowest risk } \\
\text { CAN score }<90\end{array}$} & \multicolumn{2}{|c|}{$\begin{array}{l}\text { Moderate risk } \\
\text { CAN score 90-94 }\end{array}$} & \multicolumn{2}{|c|}{$\begin{array}{l}\text { High risk } \\
\text { CAN score 95-97 }\end{array}$} & \multicolumn{2}{|c|}{$\begin{array}{l}\text { Highest risk } \\
\text { CAN score 98-99 }\end{array}$} & \multicolumn{2}{|c|}{$\begin{array}{l}\text { Missing CAN score } \\
\text { Undetermined risk }\end{array}$} \\
\hline & Total $N$ & $\begin{array}{l}\text { GoCC: } \\
\text { \% yes }\end{array}$ & Total $N$ & $\begin{array}{l}\text { GoCC: } \\
\text { \%yes }\end{array}$ & Total $N$ & $\begin{array}{l}\text { GoCC: } \\
\text { \%yes }\end{array}$ & Total $N$ & $\begin{array}{l}\text { GoCC: } \\
\text { \% yes }\end{array}$ & Total $N$ & $\begin{array}{l}\text { GoCC: } \\
\text { \%yes }\end{array}$ \\
\hline Overall & $4,680,421$ & $<1$ & 270,900 & 6 & 164,515 & 11 & 113,014 & 24 & 347,429 & 2 \\
\hline $\begin{array}{l}\text { Patient characteristic } \\
\text { Age categories*, } N \\
\text { (\%) }\end{array}$ & $4,680,412$ & & 270,899 & & 164,515 & & 112,969 & & 347,415 & \\
\hline $\begin{array}{l}<65 \\
65-70 \\
71-80 \\
81-90 \\
>90 \\
\text { Mean age (years) }\end{array}$ & $\begin{array}{l}2,285,024 \\
903,458 \\
987,940 \\
419,000 \\
84,990\end{array}$ & $\begin{array}{l}<1 \\
<1 \\
1 \\
2 \\
3 \\
70.22\end{array}$ & $\begin{array}{l}92,653 \\
65,199 \\
68,963 \\
34,564 \\
9520\end{array}$ & $\begin{array}{l}4 \\
6 \\
7 \\
9 \\
13 \\
72.25\end{array}$ & $\begin{array}{l}52,877 \\
38,967 \\
42,089 \\
23,903 \\
6679\end{array}$ & $\begin{array}{l}8 \\
11 \\
13 \\
16 \\
21 \\
72.64\end{array}$ & $\begin{array}{l}32,427 \\
25,381 \\
28,479 \\
20,226 \\
6456\end{array}$ & $\begin{array}{l}17 \\
23 \\
26 \\
32 \\
39 \\
74.30\end{array}$ & $\begin{array}{l}174,548 \\
45,618 \\
68,058 \\
44,975 \\
14,216\end{array}$ & $\begin{array}{l}<1 \\
2 \\
2 \\
3 \\
4 \\
74.38\end{array}$ \\
\hline Gender & & & & & & & & & & \\
\hline $\begin{array}{l}\text { Male } \\
\text { Female }\end{array}$ & $\begin{array}{l}4,257,885 \\
422536\end{array}$ & $<1$ & $\begin{array}{l}252,153 \\
18,747\end{array}$ & $\begin{array}{l}6 \\
4\end{array}$ & 155,510 & 12 & 108,497 & 24 & $\begin{array}{l}318,633 \\
28796\end{array}$ & 2 \\
\hline Race/ethnicity & & & & & & 9 & & & & \\
\hline Caucasian & $3,163,913$ & $<1$ & 181,818 & 7 & 109,855 & 12 & 73,455 & 26 & 211,325 & 2 \\
\hline African American & 802,223 & $<1$ & 57,196 & 4 & 35,891 & 8 & 26,942 & 19 & 43,150 & 2 \\
\hline Hispanic or Latino & 308,250 & $<1$ & 15,528 & 6 & 9414 & 12 & 6792 & 27 & 18,414 & 1 \\
\hline $\begin{array}{l}\text { American Indian or } \\
\text { Alaskan Native }\end{array}$ & 43,765 & $<1$ & 2505 & 5 & 1521 & 11 & 955 & 24 & 4030 & $<1$ \\
\hline Asian & 55,324 & $<1$ & 1266 & 4 & 678 & 7 & 359 & 21 & 4430 & $<1$ \\
\hline $\begin{array}{l}\text { Native Hawaiian or } \\
\text { other Pacific Islander }\end{array}$ & 40,800 & $<1$ & 2215 & 5 & 1198 & 11 & 775 & 24 & 2462 & 1 \\
\hline $\begin{array}{l}\text { Unknown or } \\
\text { declined to answer }\end{array}$ & 266,146 & $<1$ & 10,372 & 6 & 5958 & 11 & 3736 & 23 & 63,618 & $<1$ \\
\hline Marital status & & & & & & & & & & \\
\hline Married & $2,650,890$ & $<1$ & 116,874 & 7 & 65,904 & 13 & 40,048 & 27 & 160,889 & 1 \\
\hline Divorced & 962,000 & $<1$ & 82,861 & 5 & 52,743 & 10 & 337,479 & 22 & 46,932 & 3 \\
\hline Widowed & 193,000 & 2 & 22,579 & 8 & 15,823 & 15 & 13,941 & 30 & 14,431 & 4 \\
\hline Never married & 606,479 & $<1$ & 34,551 & 5 & 21,399 & 9 & 15,145 & 20 & 44,156 & 2 \\
\hline Separated & 139,274 & $<1$ & 12,651 & 4 & 7932 & 9 & 5952 & 19 & 7631 & 2 \\
\hline Unknown & 128,778 & $<1$ & 1384 & 7 & 714 & 14 & 449 & 29 & 73,390 & $<1$ \\
\hline JEN $^{\mathrm{TM}}$ Frailty Index & $4,680,421$ & 5.59 & 270,900 & 6.68 & 164,515 & 7.27 & 113,014 & 8.24 & 347,429 & 7.37 \\
\hline Hierarchical & $4,680,421$ & 2.16 & 270,900 & 2.96 & 164,515 & 3.59 & 113,014 & 4.90 & 347,429 & 4.04 \\
\hline $\begin{array}{l}\text { Category Condition } \\
\text { score }\end{array}$ & & & & & & & & & & \\
\hline Facility characteristics & & & & & & & & & & \\
\hline VAMC urban/rural cla & sification, $N$ & & & & & & & & & \\
\hline Urban & $4,272,784$ & $<1$ & 252,007 & 6 & 154,432 & 12 & 107,202 & 24 & 325,648 & 1 \\
\hline Rural & 407,637 & $<1$ & 18,893 & 5 & 10,083 & 9 & 5812 & 22 & 21,781 & 2 \\
\hline Facility complexity, $N$ & & & & & & & & & & \\
\hline Level 1a, 1b, 1c & $3,741,633$ & $<1$ & 224,737 & 6 & 139,178 & 12 & 98,551 & 25 & 285,156 & 2 \\
\hline Level 2, 3 & 938,788 & $<1$ & 46,163 & 5 & 25,337 & 10 & 14,463 & 21 & 62,273 & 1 \\
\hline
\end{tabular}

Due to the large sample size, statistical tests were statistically significant at the $p<0.001$ level but not clinically meaningful

*Age missing for some subjects

CI 0.83-0.96; Asian OR 0.59, 95\% CI 0.53-0.66; unknown OR $0.84,95 \%$ CI $0.81-0.87$ ), female gender (OR $0.92,95 \%$ CI $0.89-0.95)$, rural location $(0.76,95 \%$ CI0.73-0.78), and care in a low-complexity facility (OR $0.63,95 \%$ CI $0.62-0.64$ ) were associated with lower odds of completion.

Documented treatment preferences are summarized in Table 3. Between 43 and $54 \%$ of veterans' goals of care focused on maintaining function and independence, and $41-64 \%$ focused on comfort. The preference for comfort increased for veterans with higher CAN scores, whereas the desire to prolong life decreased with higher CAN scores. Over half of veterans (56\%) with the lowest CAN scores wanted CPR whereas $43 \%$ with the highest scores wanted CPR. In templates containing data for non-required elements $(N=69,557)$, trends were similar for non-cardiopulmonary events; that is, more veterans in the higher
CAN groups or their surrogates chose to limit other LSTs. Preferences to limit or forgo other LSTs such as artificial nutrition, hydration, hospitalizations, and ICU transfers did not differ significantly among different CAN score groups.

Among veterans who selected "to be comfortable" as a goal of care, most chose to forego CPR; however, one in four veterans who selected a goal of comfort also wanted cardiopulmonary resuscitation. A similar pattern was observed for other LSTs; approximately $23 \%$ of veterans who selected a goal of comfort indicated that they also preferred a full scope of treatment (data not shown).

Appendix Figure 3 summarizes trends in LST template completion over the first 7 months of implementation. Rates of new LST templates and orders were fairly consistent, averaging approximately 11,000 templates monthly. The 
Table 2 Patient- and Facility-Level Predictors of Goals of Care Conversations Documented in a Life-Sustaining Treatment Template

\begin{tabular}{llll}
\hline \hline Covariates & $\begin{array}{l}\text { Odds } \\
\text { ratio }\end{array}$ & $\begin{array}{l}\text { Lower 95\% } \\
\text { CI }\end{array}$ & $\begin{array}{l}\text { Upper 95\% } \\
\text { CI }\end{array}$ \\
\hline
\end{tabular}

Care Assessment Need (CAN) score category

Reference: CAN scores $0-89$

$\begin{array}{llll}\text { CAN scores 90-94 } & 1.67 & 1.64 & 1.71 \\ \text { CAN scores 95-97 } & 2.38 & 2.33 & 2.42 \\ \text { CAN scores 98-99 } & 4.23 & 4.14 & 4.31 \\ \text { Missing CAN score } & 1.82 & 1.75 & 1.89\end{array}$

VA nursing home stay

Reference: no VA nursing home stay

VA nursing home stay $14.54 \quad 14.12$

Hierarchical Condition Category ( $\mathrm{HCC}$ ) category

Reference: HCC score 1 st quartile $0<0.38$

HCC score 2nd quartile $1.47 \quad 1.38$

$0.38-<0.65$

HCC score 3rd quartile $\quad 2.75 \quad 2.60$

$0.65-<1.11$

HCC score 4th quartile $\quad 8.61$

$8.14 \quad 9.11$

$1.11-16.63$

$\mathrm{JEN}^{\mathrm{TM}}$ Frailty Index category

Reference: JFI scores $0-2$

\begin{tabular}{|c|c|c|c|}
\hline JFI scores 3-5 & 3.70 & 3.54 & 3.86 \\
\hline JFI scores $6-13$ & 12.53 & 11.99 & 13.1 \\
\hline \multicolumn{4}{|l|}{ ge category } \\
\hline \multicolumn{4}{|l|}{ eference: age $\leq 64$} \\
\hline Age $71-80$ & 1.10 & 1.01 & \\
\hline Age $81-90$ & 1.69 & 1.20 & 1.73 \\
\hline Age $\geq 91$ & 2.43 & 2.35 & 2.50 \\
\hline \multicolumn{4}{|l|}{ Marital status } \\
\hline \multicolumn{4}{|l|}{ eference: married } \\
\hline Divorced & 1.19 & 1.17 & 1.21 \\
\hline Widowed & 1.22 & 1.19 & 1.25 \\
\hline Never married & 1.21 & 1.18 & 1.24 \\
\hline Separated & 1.13 & 1.09 & 1.18 \\
\hline Unknown & 1.36 & 1.28 & 1.44 \\
\hline \multicolumn{4}{|l|}{ Race/ethnicity } \\
\hline \multicolumn{4}{|l|}{ Reference: Caucasian } \\
\hline African American & 0.70 & 0.69 & 0.72 \\
\hline Hispanic & 0.87 & 0.85 & 0.90 \\
\hline American Indian/Alaskan & 0.89 & 0.83 & 0.96 \\
\hline \multicolumn{4}{|l|}{ Jative } \\
\hline Asian & 0.59 & 0.53 & 0.66 \\
\hline $\begin{array}{l}\text { Native Hawaiian/Pacific } \\
\text { slander }\end{array}$ & 0.78 & 0.72 & 0.8 \\
\hline Unknown/declined to & 0.84 & 0.81 & 0.8 \\
\hline
\end{tabular}

state

Gender

Reference: male

$\begin{array}{llll}\text { Female } & 0.92 & 0.89 & 0.95\end{array}$

Urban/rural (location where veterans received majority of care)

Reference: urban

$\begin{array}{llll}\text { Rural } & 0.76 & 0.74 & 0.78\end{array}$

Facility complexity

Reference: level 1A, 1B, 1C

$\begin{array}{llll}\text { Levels } 2 \text { and } 3 & 0.63 & 0.62 & 0.64\end{array}$

Adjusted for CAN scores, VA nursing home stay, HCC score, JEN ${ }^{\mathrm{TM}}$ Frailty Index score, age, marital status, racelethnicity, gender, rurality, and facility complexity

proportion of templates that went beyond the required four elements was also consistent ( $\approx 84 \%$ across all months).

\section{DISCUSSION}

The LSTDI was designed to proactively elicit, document, and honor the goals, values, and LST decisions of seriously ill veterans across the VA's national healthcare system. The initiative promotes high-quality GoCC and standardized, readily accessible LST templates and orders. In the first 7 months of implementation in 137 VA facilities, over 225,000 completed LST templates among 108,145 unique veterans have been entered into the VA electronic health record. We saw expected completion patterns, in that older veterans and those at the highest risk for hospitalization or death were more likely to have a completed LST template compared with younger veterans and those in the moderate and lowest risk groups. This finding suggests that clinicians are appropriately prioritizing documentation of LST preferences with veterans experiencing serious illness who are at the highest risk for hospitalization and/or death. Nearly a quarter of those in the highest risk group completing an LST template in this early phase is encouraging but likely a higher percentage in this highest risk category should have documented LST templates. This early success may reflect the extensive training included in the multi-pronged initiative. This training included identifying high-risk patients using CAN scores and other prognostic indicators such as comorbidity and frailty, but continued work will be necessary to continue to improve and identify appropriate benchmarks. $^{22}$

Although an impressive number of LST templates were completed, the number of veterans who are eligible for LST completion (i.e., at a high risk for a life-threatening clinical event in the next 1-2 years) is difficult to determine. The LSTDI recommends having GoCCs and documenting LST preferences with specific veterans (e.g., those with high CAN scores) in certain contexts (e.g., upon admission to an inpatient unit or nursing home) $)^{22}$; nonetheless, these are guidelines, not requirements, to allow for clinician judgment. ${ }^{27}$ Thus, calculating the appropriate "denominator" for this population is a challenge, though one that is not unique to the VA. ${ }^{28,}{ }^{29}$ The VA currently is exploring using CAN scores of 95 or above to estimate of the denominator; however, like the many other available prognostic tools, the CAN score is not a perfect predictive indicator. $^{23,} 29,30$ Another measure of success is to monitor the percentage of decedents who have completed LST templates and orders. Using this and other metrics, facilities can design quality improvement initiatives. This work is ongoing and evolving.

Prior research has shown that as many as $69 \%$ of POLST forms are incomplete with at least one section that is left blank. ${ }^{31}$ In contrast, over $80 \%$ of LST templates completed in the initial phase of LSTDI implementation included documentation of non-required elements, such as preferences about hydration, antibiotics, and hospitalization. This finding suggests that clinicians are discussing preferences more comprehensively than simply the required LST template elements.

We found that a relatively consistent number of templates are completed monthly. This pattern may indicate 
Table 3 Treatment Decisions Responses by Veterans or Authorized Surrogates with Completed Life-Sustaining Treatment Templates Stratified by Care Assessment Need Scores

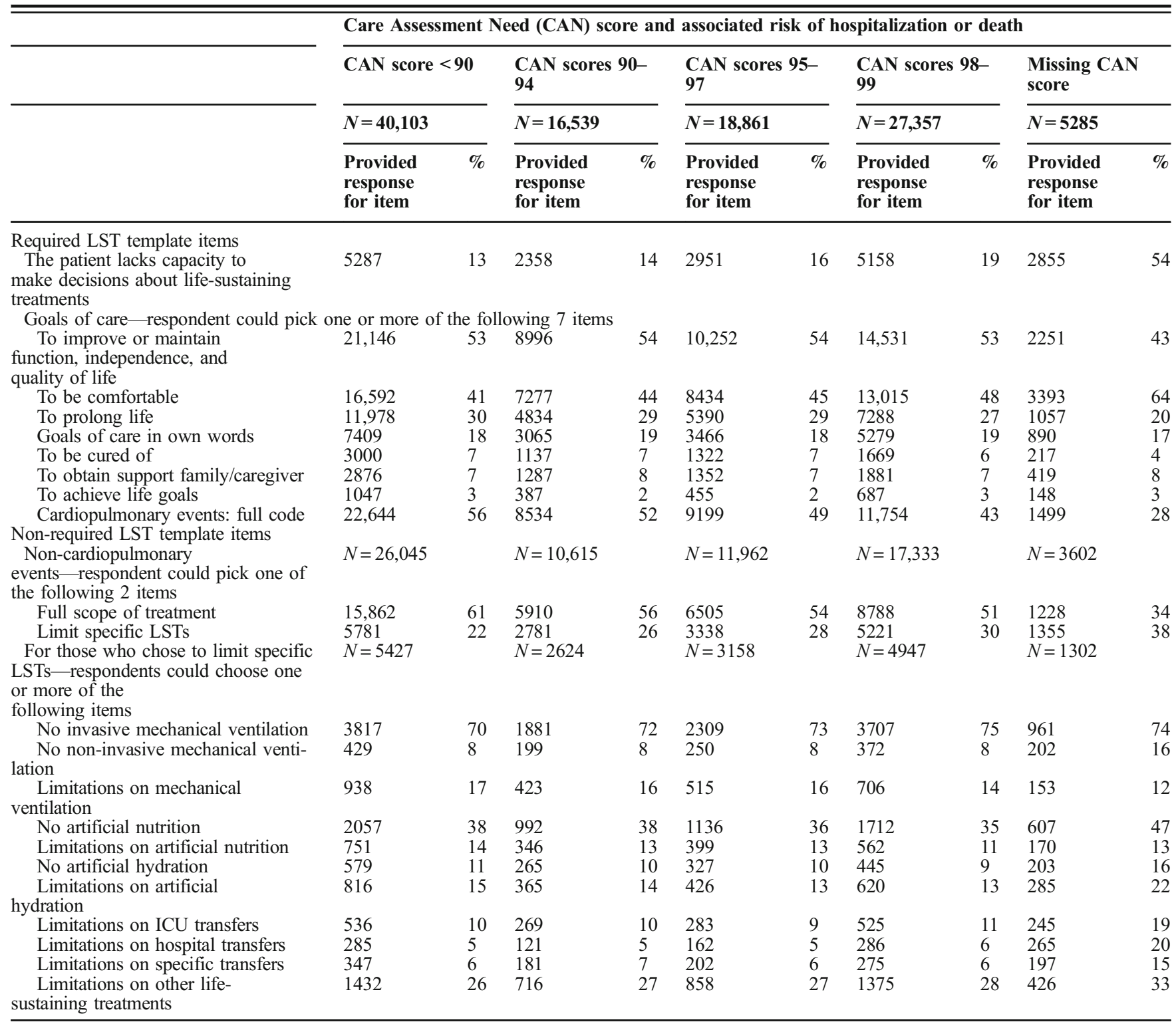

that a "steady state" has been achieved at this early stage of national implementation. It may also reflect the current limits with regard to the number of clinicians who are trained in conducting GoCCs. Palliative care specialists are often asked to conduct GoCCs with patients and families, but the current and projected shortage of specialists underscores the need to train non-palliative care clinicians. ${ }^{1,} 32$ The NCEHC addressed these needs by offering intensive train-the-trainer workshops for prescribing clinicians (i.e., physicians, nurse practitioners, and physician assistants) and other clinicians (e.g., nurses, social workers, clinical psychologists), who then conduct trainings in their home facilities. To date, over 13,000 VA clinicians have been trained in conducting GoCCs and documenting treatment preferences in the LST template (NCEHC, unpublished data). The impact on these training efforts has yet to be measured.

Approximately $25 \%$ of veterans who indicated the goal "to be comfortable" also wanted cardiopulmonary resuscitation and other LSTs such as mechanical ventilation. These dual preferences appear to be inconsistent, and similar conflicting choices have been documented in non-VA studies ${ }^{15}, 17,33$ Inconsistent choices are concerning in that they may lead to care that is not aligned with the patient's true preferences. ${ }^{31}$ Several explanations for the discrepancies are possible. For example, these choices might reflect low-quality GoCCs that left veterans without sufficient, accurate knowledge upon which to 
make informed decisions, a deficiency that has been identified in earlier studies. ${ }^{16,}{ }^{17}$ On the other hand, these choices may recognize the complex, fluid nature of a person's goals. For instance, a person may want relief from the uncomfortable side effects of chemotherapy while receiving aggressive, life-prolonging therapies. Finally, they may reflect the particular practice milieu at the VA, where veterans are not required to choose between hospice/palliative care and disease-modifying therapies, and instead may choose concurrent care. ${ }^{34}$ Research is needed to determine the degree to which inconsistent preferences for comfort and aggressive LSTs represent misunderstanding or well-considered choices.

Our analysis showed that non-Caucasian race and nonHispanic ethnicity are associated with lower odds of LST template completion, a finding that is consistent with other studies of POLST orders. ${ }^{35,}{ }^{36}$ While these differences represent statistically significant differences in LST template completion, the magnitude of the difference is lower than in non-veteran documentation of LST preferences. This may be explained by a muting of racial and ethnic disparities observed in the VA compared with other healthcare systems. ${ }^{37}$ The Office of Health Equity is collaborating with NCEHC to address the observed differences. ${ }^{38}$ Template completion was also lower among veterans in rural areas, a difference that has also been found in previous studies. ${ }^{39}$ This difference may be attributed to a lack of access to hospice and palliative care or a fundamental difference in how people from rural areas approach end-of-life care. ${ }^{40,}{ }^{41}$ The VA has an opportunity to mitigate these differences, in that veterans living in rural areas have better continuity of care with primary care providers compared with non-veterans. ${ }^{37}$ Thus, efforts to reduce rural disparities in LST completion could specifically focus efforts on rural primary care providers. Other approaches include leveraging the VA telehealth infrastructure and using group visit models to engage veterans in conversations about their goals of care. ${ }^{42}$

Limitations to this study include the unique, predominately male veteran population, which hinders generalization to other patient groups. Moreover, this analysis provides a global look at implementation. Future studies are needed to examine many aspects of the LSTDI, such as identifying barriers and facilitators to implementation. For example, as of December 18, 2019, 8\% of initial GoCCs were conducted in nursing homes, $40 \%$ in outpatient settings, and $52 \%$ in inpatient settings which may provide an opportunity to study barriers to completion in outpatient clinics and facilitators in inpatient. An additional study of the unexpected findings such as a higher likelihood of unmarried veterans completing LST templates will be needed. This analysis does not include a longitudinal analysis of trends, including changes in veterans' preferences over time ${ }^{10}$; and facility, unit, and clinician variations across the system. It also is critical to evaluate the success of the LSTDI by examining the degree to which GoCCs and LST template completion lead to concordance between care preferences and actual care delivery. Earlier studies have demonstrated generally high concordance between preferences documented on POLST forms and actual care that is delivered within the VA. ${ }^{5}$, ${ }^{41}$ Nonetheless, we have yet to examine concordance between preferences documented on LST templates and actual care provided. Finally, we did not specifically examine the quality of the GoCC that underlie the preferences documented in the LST template. This is particularly important given the evidence from other studies suggesting that POLST conversations are not uniformly of high-quality. ${ }^{16,17}$

We believe that this analysis is the first to describe early implementation of a comprehensive national program to elicit and document the values, goals, and treatment preferences for persons with serious illness. As such, the VA's multicomponent LSTDI can inform science and policy, especially vis-à-vis the use of portable LST orders (e.g., POLST). Although some states such as Oregon and Maryland, as well as Kaiser Permanente, have contributed important findings related to POLST use, ${ }^{10}, 14,27,39,43,44$ the VA experience represents a unique opportunity to examine the processes and outcomes across a large integrated healthcare system. Furthermore, the VA's commitment to implementation science has been incorporated into ongoing evaluation activities. ${ }^{45,} 46$ These studies and projects will strengthen the empirical foundations of quality improvement across the VA and other healthcare systems.

Acknowledgments: Thanks are due to Virginia Ashby Sharpe, $P h D$, Department of Veterans Affairs, National Center for Ethics in Health Care, Washington, DC, USA; Anne E. Sales, PhD RN, VA Ann Arbor Center for Clinical Management Research and Department of Learning Health Sciences, University of Michigan Medical School, Ann Arbor, MI, USA; In addition, the Geriatric and Extended Care Data Analysis Center (GECDAC) programming team provided code to extract data, including code that was adapted by GECDAC from the Women's Health Evaluation Initiative.

Corresponding Author: Cari Levy, MD, PhD; Department of Veterans Affairs, Rocky Mountain VA Medical Center, Aurora, CO, USA (e-mail: Cari.Levy@va.gov).

\section{Compliance with Ethical Standards:}

The VA Office of Research and Development determined that this analysis was for quality improvement and not subject to human research regulations; thus, no IRB approval was obtained.

Conflict of Interest: All authors are supported by a Veterans Health Administration, Quality Enhancement Research Initiative (QUE 15288) grant.

Disclaimer: The views expressed in this article are those of the author(s) and do not necessarily represent the views of the Department of Veterans Affairs. 


\section{Appendix}

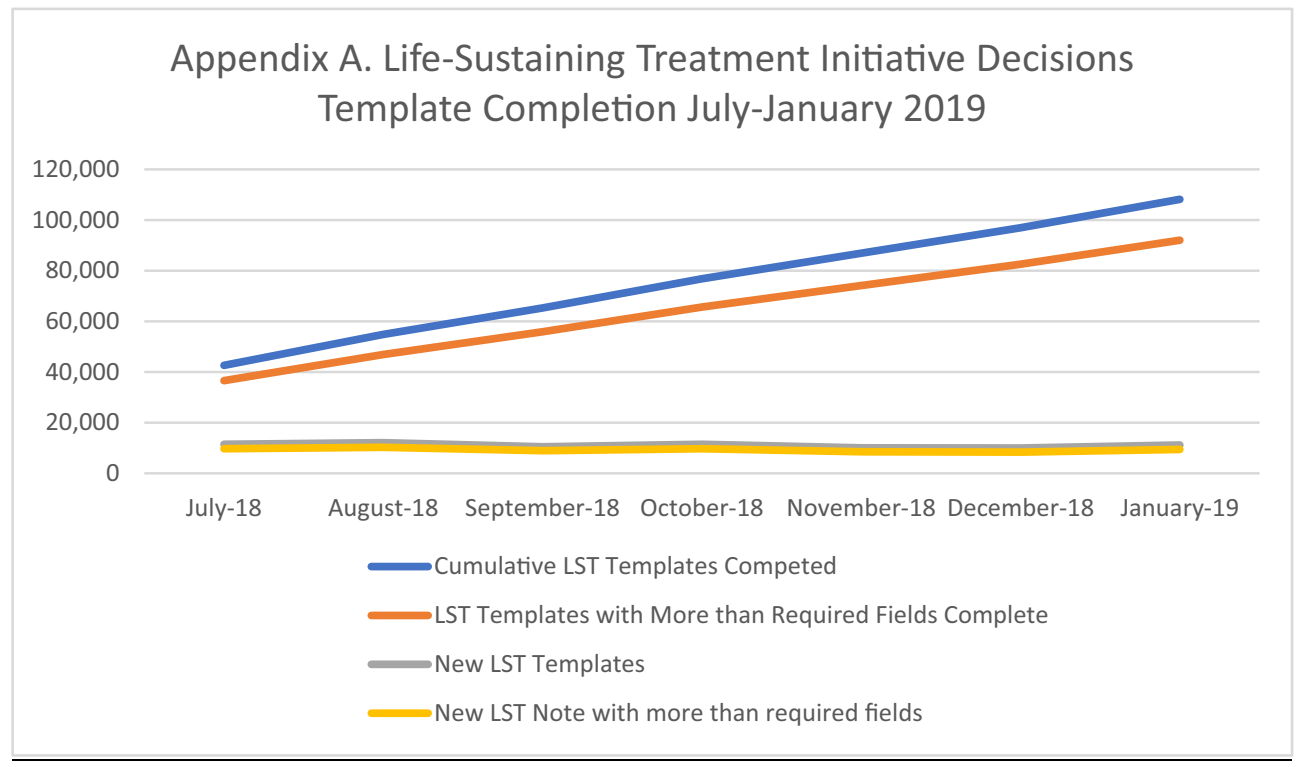

Figure 3 Life-Sustaining Treatment initiative decisions template completion July-January 2019.

\section{REFERENCES}

1. Institute of Medicine. Dying in America: Improving quality and honoring individual preferences near the end of life. Washington 2015.

2. National Consensus Project for Quality Palliative Care. Clinical Practice Guidelines for Quality Palliative Care. 2018.

3. Fromme EK, Zive D, Schmidt TA, Cook JN, Tolle SW. Association between Physician Orders for Life-Sustaining Treatment for Scope of Treatment and in-hospital death in Oregon. J Am Geriatr Soc. 2014;62(7): 1246-51.

4. Hickman SE, Nelson CA, Moss AH, Tolle SW, Perrin NA, Hammes BJ. The consistency between treatments provided to nursing facility residents and orders on the physician orders for life-sustaining treatment form. $J$ Am Geriatr Soc. 2011;59(11):2091-9.

5. Richardson DK, Fromme E, Zive D, Fu R, Newgard CD. Concordance of out-of-hospital and emergency department cardiac arrest resuscitation with documented end-of-life choices in Oregon. Ann Emerg Med. 2014;63(4):375-83.

6. Hickman SE, Nelson CA, Perrin NA, Moss AH, Hammes BJ, Tolle Sw A comparison of methods to communicate treatment preferences in nursing facilities: traditional practices versus the physician orders for life-sustaining treatment program. J Am Geriatr Soc. 2010;58(7): 1241-8.

7. Pedraza SL, Culp S, Knestrick M, Falkenstine E, Moss AH. Association of Physician Orders for Life-Sustaining Treatment Form Use With End-ofLife Care Quality Metrics in Patients With Cancer. J Oncol Pract. 2017;13(10):e881-e8.

8. Nugent SM, Slatore CG, Ganzini L, Golden SE, Zive D, Vranas KC, et al. POLST Registration and Associated Outcomes Among Veterans With Advanced-Stage Lung Cancer. Am J Hosp Palliat Care. 2019;36(7):564-70.

9. Zive DM, Jimenez VM, Fromme EK, Tolle SW. Changes Over Time in the Oregon Physician Orders for Life-Sustaining Treatment Registry: A Study of Two Decedent Cohorts. J Palliat Med. 2019;22(5):500-7.

10. Hopping-Winn J, Mullin J, March L, Caughey M, Stern M, Jarvie J. The Progression of End-of-Life Wishes and Concordance with End-of-Life Care. J Palliat Med. 2018;21(4):541-5.

11. Auriemma CL, Nguyen CA, Bronheim R, Kent S, Nadiger S, Pardo D, et al. Stability of end-of-life preferences: a systematic review of the evidence. JAMA Intern Med. 2014;174(7):1085-92.

12. Zive DM, Fromme EK, Schmidt TA, Cook JN, Tolle SW. Timing of POLST Form Completion by Cause of Death. J Pain Symptom Manage. 2015;50(5):650-8.
13. Lewis E, Cardona-Morrell M, Ong KY, Trankle SA, Hillman K. Evidence still insufficient that advance care documentation leads to engagement of healthcare professionals in end-of-life discussions: A systematic review. Palliat Med. 2016;30(9):807-24.

14. Moss AH, Zive DM, Falkenstine EC, Dunithan C. The Quality of POLST Completion to Guide Treatment: A 2-State Study. J Am Med Dir Assoc. 2017;18(9):810 e5-e9.

15. Rahman AN, Bressette M, Enguidanos S. Quality of Physician Orders for Life-Sustaining Treatment Forms Completed in Nursing Homes. J Palliat Med. 2017;20(5):538-41.

16. Kim H, Bradway C, Hickman SE, Ersek M. Exploring providersurrogate communication during POLST discussions for individuals with advanced dementia. Aging Ment Health. 2018 2:1-11.

17. Hickman SE, Hammes BJ, Torke AM, Sudore RL, Sachs GA. The Quality of Physician Orders for Life-Sustaining Treatment Decisions: A Pilot Study. J Palliat Med. 2017;20(2):155-62.

18. Mirarchi FL, Cammarata C, Zerkle SW, Cooney TE, Chenault J, Basnak D. TRIAD VII: do prehospital providers understand Physician Orders for Life-Sustaining Treatment documents? J Patient Saf. 2015;11(1):9-17.

19. Mirarchi FL, Doshi AA, Zerkle Sw, Cooney TE. TRIAD VI: how well do emergency physicians understand Physicians Orders for Life Sustaining Treatment (POLST) forms? J Patient Saf. 2015;11(1):1-8.

20. Ersek M, Hickman SE, Thomas AC, Bernard B, Unroe KT. Stakeholder Perspectives on the Optimizing Patient Transfers, Impacting Medical Quality, and Improving Symptoms: Transforming Institutional Care (OPTIMISTIC) Project. Gerontologist. 2018;58(6):1177-87.

21. U.S. Department of Veterans Affairs. Life-Sustaining Treatment Decisions: Eliciting, Documenting and Honoring Patients' Values, Goals and Preferences 2017 07/14/2019 07/14/2019]. Available from: https:// vaww.ethics.va.gov/policy.asp. Accessed 19 Nov 2019.

22. Foglia MB, Lowery J, Sharpe VA, Tompkins P, Fox E. A Comprehensive Approach to Eliciting, Documenting, and Honoring Patient Wishes for Care Near the End of Life: The Veterans Health Administration's LifeSustaining Treatment Decisions Initiative. Jt Comm J Qual Patient Saf. 2019;45(1):47-56.

23. Wang L, Porter B, Maynard C, Evans G, Bryson C, Sun H, et al. Predicting risk of hospitalization or death among patients receiving primary care in the Veterans Health Administration. Med Care. 2013;51(4):368-73. 
24. Wong ES, Yoon J, Piegari RI, Rosland AM, Fihn SD, Chang ET. Identifying Latent Subgroups of High-Risk Patients Using Risk Score Trajectories. J Gen Intern Med. 2018;33(12):2120-6.

25. Kinosian $\mathbf{B}$, Wieland $\mathbf{D}$, Gu $\mathbf{X}$, Stallard $\mathbf{E}$, Phibbs CS, Intrator 0 Validation of the JEN frailty index in the National Long-Term Care Survey community population: identifying functionally impaired older adults from claims data. BMC Health Serv Res. 2018;18(1):908.

26. Empire BlueCross. CMS-HCC Risk Adjustment Model (V22). In: Crosswalk I-CtC-H, editor.: Blue Cross and Blue Shield Association; 2018

27. Tarzian AJ, Cheevers NB. Maryland's Medical Orders for Life-Sustaining Treatment Form Use: Reports of a Statewide Survey. J Palliat Med. 2017;20(9):939-45.

28. Dy SM, Herr K, Bernacki RE, Kamal AH, Walling AM, Ersek M, et al Methodological Research Priorities in Palliative Care and Hospice Quality Measurement. J Pain Symptom Manage. 2016;51(2):155-62.

29. Kelley AS, Bollens-Lund E. Identifying the Population with Serious Illness: The "Denominator" Challenge. J Palliat Med. 2018;21(S2):S7-S16.

30. Wang L, Porter B, Maynard C, Bryson C, Sun H, Lowy E, et al. Predicting risk of hospitalization or death among patients with heart failure in the veterans health administration. Am J Cardiol. 2012;110(9):1342-9.

31. Clemency B, Cordes CC, Lindstrom HA, Basior JM, Waldrop DP. Decisions by Default: Incomplete and Contradictory MOLST in Emergency Care. J Am Med Dir Assoc. 2017;18(1):35-9.

32. Mitchell S, Tan A, Moine S, Dale J, Murray SA. Primary palliative care needs urgent attention. BMJ. 2019;365:11827.

33. Schmidt TA, Zive D, Fromme EK, Cook JN, Tolle SW. Physician orders for life-sustaining treatment (POLST): lessons learned from analysis of the Oregon POLST Registry. Resuscitation. 2014;85(4):480-5.

34. Mor V, Joyce NR, Cote DL, Gidwani RA, Ersek M, Levy CR, et al. The rise of concurrent care for veterans with advanced cancer at the end of life. Cancer. 2016;122(5):782-90.

35. MacKenzie MA, Smith-Howell E, Bomba PA, Meghani SH. Respecting Choices and Related Models of Advance Care Planning: A Systematic Review of Published Evidence. Am J Hosp Palliat Care. 2018;35(6):897907

36. Hickman SE, Torke AM, Sachs GA, Sudore RL, Myers AL, Tang Q, et al. A Tool to Assess Patient and Surrogate Knowledge about the POLST (Physician Orders for Life-Sustaining Treatment) Program. J Pain Symptom Manage. 20197.

37. Health Services Research \& Development Service. Prevalence of and interventions to reduce health disparities in vulnerable veteran popula- tions: A map of the evidence. Portland, OR: Department of Veterans Affairs; 2017 [cited 2019 August 6]; Available from: https://www.hsrd. research.va.gov/publications/esp/DisparitiesInterventions.pdf. Accessed 19 Nov 2019.

38. Korshak L, Foglia MB. Improving Health Care Decision Making Near the End of Life Fact Sheet. www.va.gov: U.S. Department of Veterans Affairs; 2019 [cited 2019]; Available from: https://www.va.gov/HEALTHEQUITY/ docs/Health_Care_Decisions_Fact_Sheet.pdf. Accessed 19 Nov 2019.

39. Fromme EK, Zive D, Schmidt TA, Olszewski E, Tolle sw. POLST Registry do-not-resuscitate orders and other patient treatment preferences. JAMA. 2012;307(1):34-5.

40. Carlson MDA, Bradley EH, Du Q, Morrison RS. Geographic Access to Hospice in the United States. J Palliat Med. 2010 13(11):1331-1338.

41. Gessert CE, Elliott BA, Peden-McAlpine C. Family decision-making for nursing home residents with dementia: rural-urban differences. J Rural Health. 2006 22(1):1-8

42. U.S. Department of Veterans Affairs. Rural Promising Practice Issue Brief: Transforming Advance Care Planning into an Atmosphere of Support and Communication2017:[5 p.]. Available from: https://www.ruralhealth.va. gov/docs/promise/Advanced_Care_Planning_Brief_4.04.17.pdf. Accessed 19 Nov 2019.

43. Hickman SE, Tolle SW, Brummel-Smith K, Carley MM. Use of the Physician Orders for Life-Sustaining Treatment program in Oregon nursing facilities: beyond resuscitation status. J Am Geriatr Soc. 2004;52(9): 1424-9.

44. Schmidt TA, Olszewski EA, Zive D, Fromme EK, Tolle Sw. The Oregon physician orders for life-sustaining treatment registry: a preliminary study of emergency medical services utilization. J Emerg Med. 2013;44(4):796-805

45. Carpenter J, Miller SC, Kolanowski AM, Karel MJ, Periyakoil vS, Lowery $\mathbf{J}$, et al. Partnership to Enhance Resident Outcomes for Community Living Center Residents With Dementia: Description of the Protocol and Preliminary Findings. J Gerontol Nurs. 2019;45(3):21-30.

46. Sales AE, Ersek M, Intrator OK, Levy C, Carpenter JG, Hogikyan R, et al. Implementing goals of care conversations with veterans in VA longterm care setting: a mixed methods protocol. Implement Sci. 2016;11(1):132.

Publisher's Note Springer Nature remains neutral with regard to jurisdictional claims in published maps and institutional affiliations. 